\title{
AC 2010-1761: BROADENING STUDENT RESEARCH EXPERIENCES THROUGH SUMMER EXCHANGE PROGRAM ACROSS CAMPUSES
}

\author{
Abhijit Nagchaudhuri, University of Maryland, Eastern Shore \\ Abhijit Nagchaudhuri is a Professor in the Department of Engineering and Aviation Sciences at \\ University of Maryland Eastern Shore. Prior to joining UMES he worked in Turabo University in \\ San Juan, PR as well as Duke University in Durham North Carolina as Assistant Professor and \\ Research Assistant Professor, respectively. Dr. Nagchaudhuri is a member of ASME and ASEE \\ professional societies and is actively involved in teaching and research in the fields of \\ engineering mechanics, robotics, systems and control, design of mechanical and mechatronic \\ systems, precision agriculture and remote sensing. Dr. Nagchaudhuri received his bachelors \\ degree from Jadavpur University in Calcutta, India with a honors in Mechanical Engineering in \\ 1983, thereafter, he worked in a multinational industry for 4 years before joining Tulane \\ University as a graduate student in the fall of 1987. He received his M.S. degree from Tulane \\ University in 1989 and Ph.D. degree from Duke University in 1992.
}

\section{Terry Teays, Johns Hopkins University}

Terry decided to become an astronomer when he was eight years old. He received his Bachelor's degree from the University of California at Santa Cruz, and his Ph. D. from the University of Nebraska - Lincoln. He spent much of his career conducting research on stars that pulsate and working with NASA spacecraft. Later he became involved in managing scientific projects. He served as the director of a scientific research center for a major corporation and operated his own consulting firm.

In recent years he has been focused on issues of space science education. He was in charge of education activities for the Hubble Space Telescope and later became the Director of NASA's Origins Education Forum. He has served as the Assistant Director for Maryland Space Grant Consortium since March, 2006.

\section{Guangming Chen, Morgan State University}

Dr. Chen is an associate professor in Industrial Engineering (IE) at Morgan State University (MSU) and an interim director of the Systems Engineering and Management Institute (SEMI) that was established in spring 2009 by the Center of Excellence in Systems Engineering for Space Exploration Technologies (CESET, a \$5 million NASA grant awarded to MSU). As a co-PI of CESET and the interim director of SEMI, Dr. Chen has worked closely with the NASA engineers of Godard Space Flight Center (GSFC) on the systems engineering curriculum development. Also during 1999-2006, Dr. Chen worked with NASA's ST-5 (Space Technology 5) project at GSFC, supported by NASA Administrator's Fellowship, several NASA grants, and NASA/ASEE summer faculty fellowship. He joined GSFC ST-5 proposal writing team in summer 1999 and also worked with ST-5 project team during ST-5 implementation period: conceptual development, preliminary design, critical design and manufacturing, until the successful launch of the ST-5 micro-sat trio. He received his Ph.D. in IE from Wayne State University, a M.S. in systems engineering and a B.S. in electrical engineering from Shanghai Jiao Tong University.

\section{Mary Bowden, University of Maryland at College Park}

Mary L. Bowden is a Visiting Assistant Professor and Keystone Instructor in the Aerospace Engineering Department at the University of Maryland in College Park(UMCP), where she specializes in teaching undergraduates Statics, Mechanics of Materials, and Aerospace Structures Courses. She received her Bachelor of Arts degree in Mathematics from Cornell University in 1978, and both her Master of Science in 1981 and Doctor of Science in 1988 from the Department of Aeronautics and Astronautics at the Massachusetts Institute of Technology. After graduation, Dr. Bowden spent 10 years working in the aerospace industry for a number of 
different companies including American Composites Company, American Rocket Company, and AEC-Able Engineering. Dr. Bowden is currently Director of the Balloon Payload Program at UMCP, which was initiated 6 years ago and has been sponsored by the Maryland Space Grant Consortium since then.

\section{Richard Henry, Johns Hopkins University}

Richard Conn Henry is a Professor in the Henry A. Rowland Department of Physics and Astronomy at The Johns Hopkins University, Baltimore, where he is also Director, Maryland Space Grant Consortium, and member, Principal Professional Staff,The Johns Hopkins University Applied Physics Laboratory. Henry is also President of The Henry Foundation, Inc., a 501(c)(3) incorporated in Maryland, devoted to the advance of education and career development for the American people. Dick is also President of the Streit Council for a Union of Democracies (founded 1939 by Clarence Streit). Dick has authored more than 200 publications, including research papers in theoretical astrophysics, observational astronomy, radio astronomy, ultraviolet astronomy, and X-ray astronomy; and one book, "Atlas of the Ultraviolet Sky" (Johns Hopkins University Press). Professor Henry obtained his Bachelors and Master's degrees from University of Toronto, and doctoral degree from from Princeton University ( Astronomy) in 1967. 


\title{
Broadening Student Research Experiences Through a Summer Exchange Program across Campuses
}

\begin{abstract}
Maryland Space Grant Consortium (MDSGC) was one of the awardees of the NASA Minority Serving Institution Partnership Development program of 2009 - 2010. Facilitated by MDSGC leadership at Johns Hopkins University (JHU) and active support from NASA Goddard Space Flight Center, faculty and undergraduate students at three member institutions of MDSGC have partnered to implement a one year collaborative action plan to promote experiential learning and research efforts consistent with NASA's strategic enterprises in space and earth sciences through this venture. Two of the participating institutions, University of Maryland Eastern Shore (UMES) and Morgan State University (MSU) are Historically Black Institutions (HBI) and the third, University of Maryland College Park (UMCP), serves a large number of minority students. A major component of the partnership effort has been focused on a novel student exchange program among the three campuses. Three undergraduate engineering students were selected from each of the participating campuses to spend eight weeks of summer under the supervision of faculty advisors with active NASA related research projects at one of the other campuses. At the end of the eight weeks, each student presented their work to NASA personnel and faculty members from MDSGC affiliate institutions and other invited guests at NASA Goddard Space Flight Center (GSFC) at Greenbelt. Active involvement of MDSGC leadership at JHU, faculty at UMES, MSU and UMCP, and personnel of the Education Division of GSFC helped students. In this paper, we will highlight the novelty and learning outcomes of the student exchange program, as well as the experiential learning and research endeavors that the students participated in during the course of this program.
\end{abstract}

\subsection{Introduction}

Benefits of experiential learning and research in undergraduate engineering ${ }^{[1-3]}$ and science ${ }^{[4,5]}$ education are well documented. While fundamental concepts acquired in classroom settings can be enhanced through project work integrated within engineering courses and the culminating capstone design experience, involvement in intensive summer research internships, co-ops and exchange programs provides intellectual challenges, problem solving opportunities, and avenues to showcase innate creativity of the students in a setting that addresses broader dimensions of learning and discovery ${ }^{[6-8]}$. Recent emphasis on sensitizing students to realities of globalization has resulted in a significant increase in international exchange programs ${ }^{[9]}$. Evaluation and outcome assessment of these programs indicate that project and research experiences in an unfamiliar setting not only advance academic outcomes but afford lasting influences that 
contribute to the attainment of significant life-skills outcomes ${ }^{[10]}$. Some of the same benefits may also be acquired by setting up exchange programs for undergraduate students among neighboring universities in the same state. While some of the unique life experiences and skills that are acquired through immersion in new cultural settings are not available in summer exchange programs among students on neighboring campuses, nevertheless, a large set of academic and life-skills outcomes that parallel international exchange programs, co-ops and other similar experiences may be attained through such exposure.

The state of Maryland provides a particularly fruitful venue for exchange programs related to aerospace engineering and other areas consistent with NASA's strategic enterprises in earth and space sciences. There are a large number of academic institutions conducting research in this field as well as maintaining robust education programs. The state also has a strong vested interest in developing a capable workforce to sustain its substantial aerospace activity in the academic, government, and private sectors.

The diversity of the student population is also an important factor in Maryland. In particular, $28 \%$ of the students attending higher education institutions in Maryland are African American. The state is home to a number of HBI, two of which (UMES and MSU) are members of MDSGC. The geography of Maryland also plays a role. While the main population and a heavy concentration of high technology institutions and industries are in the Baltimore-Washington corridor, , the state also has a western "panhandle" and the Eastern Shore, which are more rural and isolated. In particular, the Eastern Shore, separated from the rest of the state by the Chesapeake Bay, is sufficiently remote that many of the students attending the other schools in the state are unfamiliar with UMES and its engineering activities.

The National Space Grant College and Fellowship (NSGCF) Act of 1988 established the space grant program, which is part of the NASA education portfolio. A space grant exists in every state; in Maryland, the Lead Institution is JHU. One of the main objectives of MDSGC is to develop the future workforce for the aerospace community in Maryland. This paper describes the results of a program to provide engineering research experience to undergraduate students from three universities that are members of MDSGC, viz., MSU, UMCP, and UMES. One of the main objectives of the program was to provide the students with an opportunity to work at another university, where they could take advantage of areas of research, faculty, and facilities that were different from those at their home institution. It was expected that this broadening of the students' experiences would be of direct benefit to them and the mentors involved. Additionally, the students would understand the opportunities available at the other institutions and the experience would give them a basis for comparison when making future higher education and/or career choices.

\subsection{Proposal Development, Planning, and Logistics}

The NSGCF Program Minority Serving Institution Partnership Development Competition was announced by NASA Headquarters in December 2008. One of the key goals of the program was to encourage greater involvement between the "Space Grants" and the minority-serving institutions in their respective states. However, the minority-serving institutions that were a part of the Maryland Space Grant program were already members of the consortium and heavily involved with the programs and projects of MDSGC. The issue was then: how do we enhance the collaboration among our members? It was decided that an exchange of students would 
produce several beneficial results: the students would be exposed to a broader range of engineering projects and techniques; the students would learn about the facilities and expertise at the other institutions; the students would receive the benefits of exciting, hands-on research projects; and the students would increase their contacts with other students and faculty in engineering. Also, the potential for greater faculty collaboration among the institutions was identified as a possible additional benefit.

With this starting concept, a program was developed to recruit three students from each of the three campuses, and place them on projects with mentors at the other campuses. The program would run for eight weeks during the summer of 2009. A group of mentors were recruited and projects were developed for each slot. Faculty representatives for the Maryland Space Grant Consortium at each campus served as the campus project manager and oversaw the arrangements at that campus. Discussions among the student applicants, mentors, campus project managers, and MDSGC staff helped develop the final assignments. The students were paid a competitive stipend and given a housing allowance, as well as travel costs to and from their internship site at the beginning and end of the summer.

It is important to note that this program was developed in a short time (there was not a lot of time between the release of the Call for Proposals and its due date). The authors feel that a crucial reason that a successful program was conceived, developed, and executed in such a short time, and resulted in great success, was due to the fact that the participants already had an established relationship. The representatives from the three host universities are also the representatives from their respective institutions to the MDSGC Program Committee, which meets regularly to consider proposals to MDSGC, programmatic issues, and strategic planning. The participants and the MDSGC management at JHU are well known to each other, know the unique facilities and research expertise at each other's institutions, and are accustomed to working together. For example, UMES has strong efforts in remote sensing for agricultural applications and autonomous platforms for studying the Chesapeake Bay; MSU has a strong program in systems engineering and participates in the MDSGC balloon payload project; while UMCP has a large aerospace engineering program, a unique neutral buoyancy facility, and spearheads the MDSGC balloon payload program. This provided a strong foundation upon which to build this new program.

Notification of the success of the proposal came in the spring before the summer of the proposed internships. It required a lot of work to assemble everything, but, again, part of the confidence that it could be pulled together in a short time was based on the past experience that the faculty members had in working together. The recruitment was facilitated by the fact that the campus project managers were all heavily involved with teaching students in hands-on projects and could use their department's resources to develop a pool of potential participants. These campus representatives did the final selection of the students to be sent to other institutions, and matched them to the projects. The projects covered a nice range of subject areas (see below), reflecting the breadth of research interests at the different universities.

Flexibility in the arrangements was a key to successful operation of the program. Schedules could be slightly adjusted, based on agreement between the student and mentor. Fiscal oversight was provided by MDSGC. In some cases, the student's housing was arranged by the faculty 
member at the host institution, and in others, the students obtained their own housing. Sufficient funds were allocated for the students to travel to conferences to present their results in the upcoming year (an often overlooked element in student internship programs).

Each student was evaluated by their mentor for the quality of their work during the summer. In addition, the students gave a formal presentation of their work at the end of the summer, which is discussed below. This seminar was hosted by NASA Goddard Space Flight Center (GSFC), a key partner of MDSGC. Overall evaluation of the program is being done by the Assistant Director of MDSGC who is also a co-author of this paper, based on input from the students and mentors. All of the mentors and students expressed satisfaction with the summer's experience. Longitudinal tracking of these students' future endeavors is also an essential part of the long term evaluation of the program's success.

In the following section a brief description of the efforts undertaken at the three host institutions, MSU, UMES and UMCP are provided with particular emphasis on the experiential learning and research endeavors of the participating students.

\subsection{Student Projects at Morgan State University}

On a competitive basis, three African-American students were selected from a pool of nine eligible applicants at MSU in May 2009 to participate in this student exchange program. Two of them were assigned to work at the UMES on specific research projects. The third student was sent to work at the UMCP. At the same time, MSU received three exchange students from the other two campuses: two students from UMCP and one student from UMES. These three exchange students assigned to Morgan State University worked with Drs. Chen, Kattel and Reece on the following three specific research projects during the summer:

\section{1) Development of a Systems Engineering Education Program at Morgan State University for NASA and the Aerospace Industry Workforce Pipeline Initiative}

As engineering systems become more complex, systems engineers are needed to integrate all systems together in order for the entire project to work properly and efficiently. Systems engineers are responsible for everything from project management and scheduling to quality control and system life time study. Systems engineering is an integral part of an engineering project. Funded through a NASA grant "Center of Excellence in Systems Engineering for Space Exploration Technologies", MSU established the Systems Engineering and Management Institute (SEMI) in May 2009. The goals of SEMI include but are not limited to: integrating systems engineering curriculum into the existing engineering education and research programs at MSU; and providing the students with an opportunity to choose a concentration or minor in systems engineering. One of the three exchange students assigned to MSU assisted Dr. Chen, the interim director of SEMI, in laying the foundation of SEMI's curriculum and developing a small case study on a systems engineering application, as well as setting up laboratory equipment, such as the flight simulator (Figure 1). 


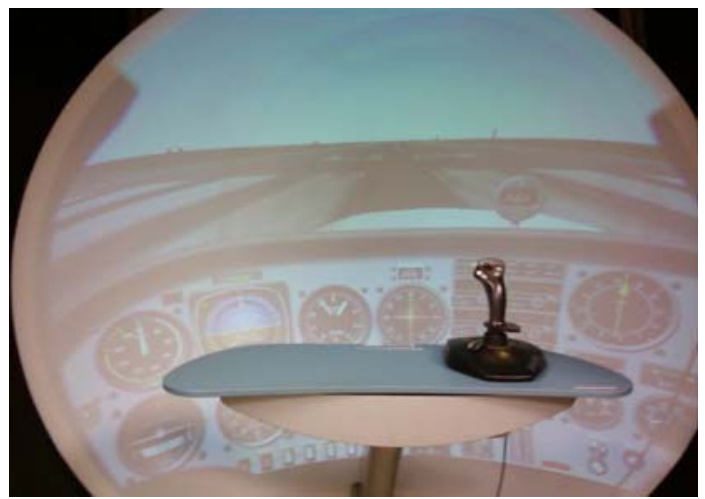

Figure1 : A flight simulator in the laboratory at Morgan State University

\section{2) Using a Low-Fidelity Simulator to Gauge Eye Reactions in Differing Weather Conditions}

The exchange student assigned to this project worked with Dr. Kattel of the Industrial Engineering Department, and explored a low-cost alternative to a flight simulator for the purpose of analyzing pilot flight reactions to different weather phenomena, and for analyzing reactions through the use of an eye-tracking package, from an ergonomic engineering perspective. The student assisted in setting up the equipment, collecting data, and performing analysis on data acquired from experiments with several human subjects who were tasked with flying the cockpit simulator (Figure 2).

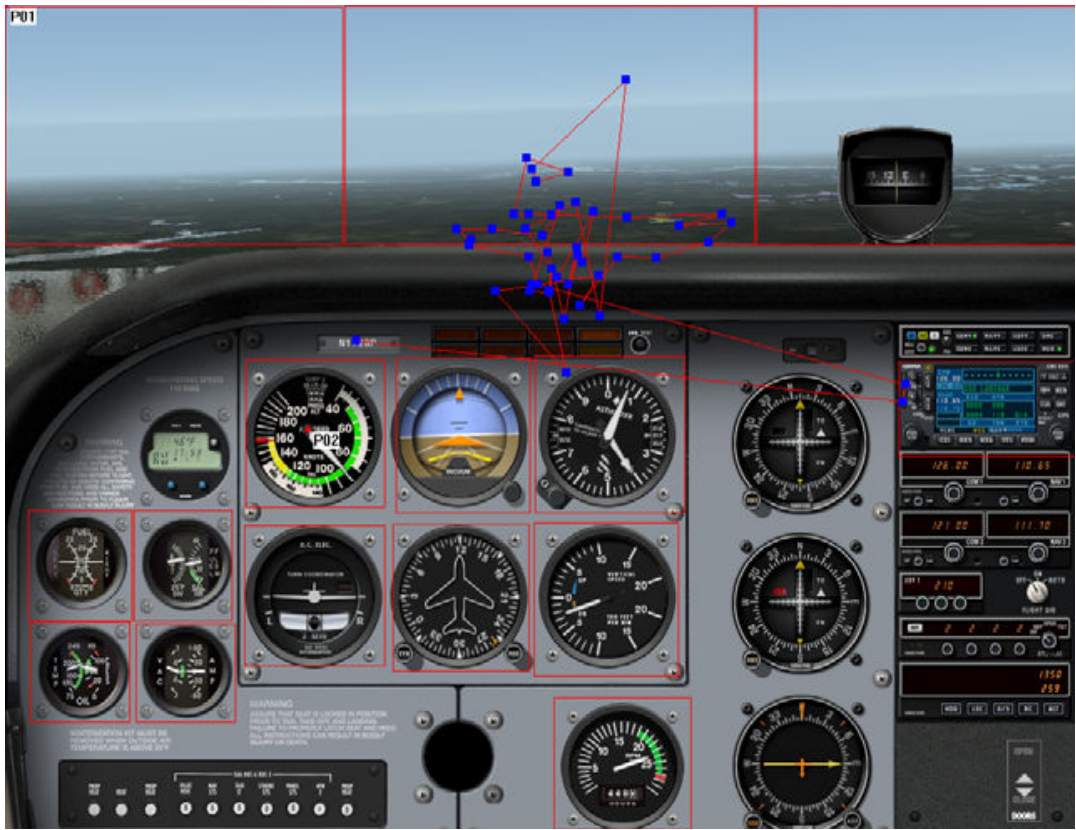

Figure 2: Data collection from a CESSNA Cockpit simulator of X-Plane 


\section{3) Using Matlab Simulink to Simulate the Performance of a Direct Receiver}

The third exchange student at Morgan State University was assigned to work with Dr. Reece of the Electrical Engineering Department on a software-defined radio project. Specifically, the student used Matlab/Simulink to simulate the performance of a direct receiver. A Software Defined Radio (SDR) is a revolutionary technology that involves minimizing the amount of hardware used in a radio system by moving the analog-to-digital and digital-to-analog converters to the RF front end. Typical radio processing will then be done digitally on a software level, as opposed to the conventional method of an analog signal going through individual hardware components, each performing a specific function. A comparison of SDR and TR (typical radio) is given in Figure 3.

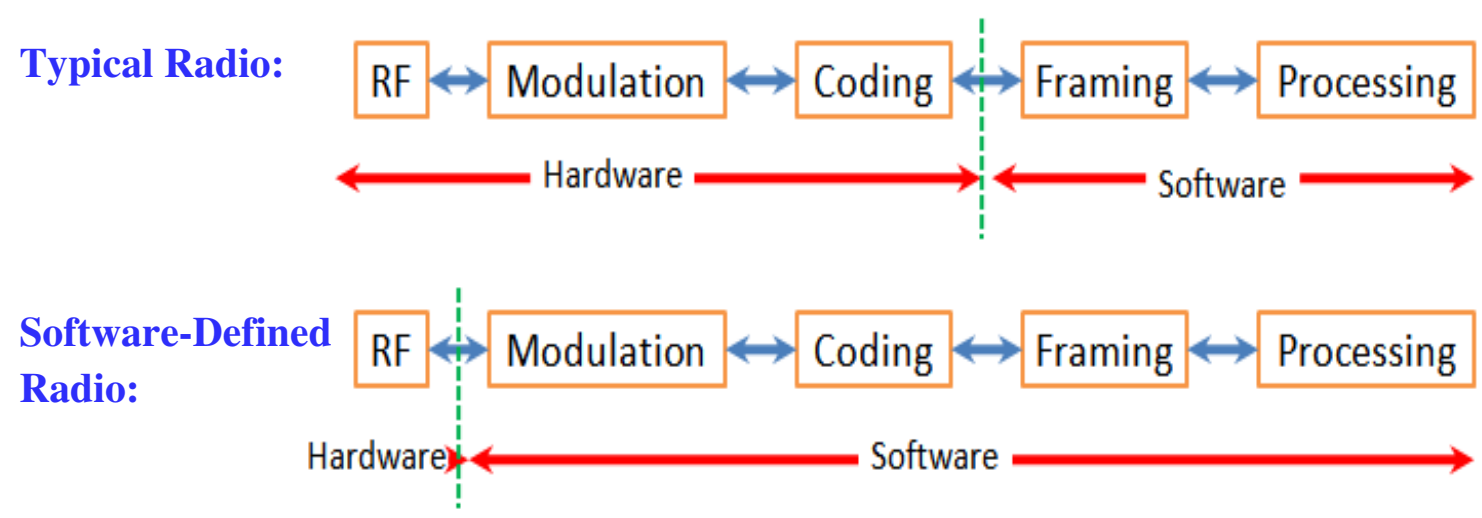

Figure 3: A comparison of SDR and TR processing.

\subsection{Student Projects at University of Maryland Eastern Shore}

In May 2009 fliers were posted at several locations to invite applications from interested students at UMES for the summer exchange program. The engineering program coordinator helped identify three engineering majors at sophomore, junior and senior levels respectively. One of them chose to work on a project at Morgan State University and the other two opted for and were assigned to two different projects at University of Maryland College Park. University of Maryland Eastern Shore received three exchange students from the other two host campuses, two from Morgan State University and one from University of Maryland College Park. Two of the exchange students teamed up to work on a new aspect of the ongoing Aerial Imaging and Remote Sensing for Precision Agriculture and Environmental Stewardship (AIRSPACES) project ${ }^{[11]}$ at UMES that is executed in close collaboration with engineers and scientists at USDA Beltsville and NASA Wallops Flight Facility, and the third student worked on a project inspired by the Ocean Atmosphere Sensor Integration System (OASIS) at NASA Wallops Flight Facility ${ }^{[12]}$. Drs. Nagchaudhuri, Yilmaz and Mitra in the Engineering, Engineering Technology, and Natural Sciences programs, respectively at UMES served as mentors for the students.

\section{1) Issues, Challenges, and Applications of Kite Aerial Imaging}

Applications involving precision agriculture and environmental stewardship at UMES have utilized a variety of platforms including manned airplanes, robotic helicopters, as well as small remote controlled unmanned aerial vehicles for remote sensing and aerial imaging. Most of this 
work has been performed in collaboration with engineers and scientists at NASA Wallops Flight Facility and integrated with the AIRSPACES project efforts at UMES. Two of the three summer exchange students at UMES teamed up to study suitability of kite aerial photography (KAP), as yet another low cost imaging platform for precision agriculture and a variety of other applications involving earth sciences, disaster surveillance, and natural resource management. The students explored wind and other environmental conditions necessary for appropriately sized kites to be aerial imaging platforms, and carried out lift and drag characterization of several kite configurations likely to be utilized for aerial imaging applications ( Figure 4a shows a Delta Kite used in the project). Laboratory and field investigations of Picavet (Figure 4b) and Aeropod (Figure 4c) platforms for KAP, were also undertaken. The exchange students were trained on ARCGIS 9.2 and exposed to a variety of software and hardware tools and equipment utilized in precision agriculture. They also learned to geo-reference, mosaic, and analyze kite aerial imagery. Dr. Yilmaz and Dr. Nagchaudhuri worked as faculty mentors for the students involved in the project. Mr. Geoffrey Bland at NASA Wallops Flight Facility also worked closely with the students.

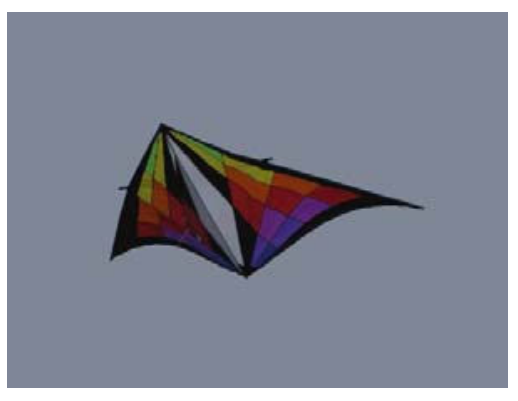

Figure 4(a) - Delta Kite

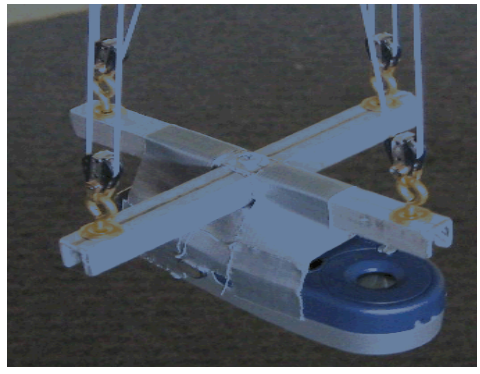

Figure 4(b) - Picavet

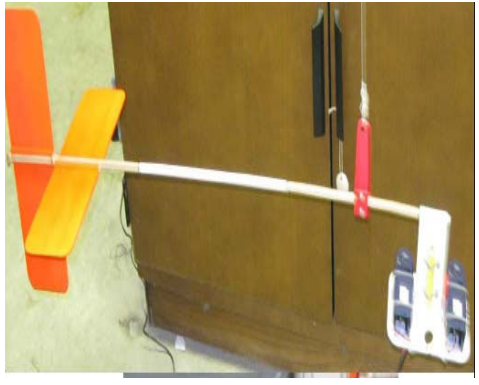

Figure 4(c) - Aeropod

\section{2) Experimental Prototype of a Remote Controlled Platform to Monitor Water Quality Data}

Eutrophication (nutrient-enrichment) leading to algal blooms is a serious threat to the coastal bays and the open oceans. As a consequence of this algal proliferation, changes in $\mathrm{pH}$, salinity, dissolved oxygen, and turbidity could impact various marine and estuarine ecosystems in an adverse manner. NASA and NOAA have collaborated on developing a solar powered autonomous surface vessel integrated with a variety of sensors to monitor ocean atmosphere interactions under the framework of the Ocean Atmosphere Sensor Integration System (OASIS) project. Dr. Nagchaudhuri had the privilege of working on the OASIS project with Dr. Moisan at NASA Wallops on a NASA fellowship over the 2004 summer during the infancy of the project. One of the exchange students worked with Dr. Mitra and Dr. Nagchaudhuri at UMES to develop a remote controlled boat (Aquabot) equipped with sensors and a GPS unit to collect water quality related data in rivers, lakes, and coastal bays. The project was inspired by the OASIS project at NASA and provided opportunities for the exchange student to get exposure to the OASIS platform (Figure 5a) and NASA scientists involved with its development. The objectives of the Aquabot project (Figure 5b) were to develop a multi-sensor remote-controlled platform for future applications in recording water quality data from the coastal bays of the Delmarva Peninsula; to analyze and compare the $\mathrm{pH}$, salinity, and dissolved oxygen data trends from the platform with the multiparameter YSI unit ${ }^{[13]}$; and to map sensor data using geospatial information technologies. A cost-effective Lego Mindstorm's NXT system in combination with a radio- 
controlled boat and Global Positioning System (GPS) was configured and developed at UMES for the purpose. The platform was utilized for preliminary tests with buoyancy, appropriate integration of sensors in laboratory settings, and also for recording data from the Assateague (Maryland) and Chincoteague (Virginia) Bays of the Delmarva Peninsula in areas where seagrass ecosystems are impacted by increased eutrophic conditions. The sensor data acquired with the platform were used in the data mapping, and were also compared to the YSI data. The prototype provided insight for future improvements for developing autonomous water quality data collection systems for lakes, rivers, and bays that would assist in water quality and pollution management issues.

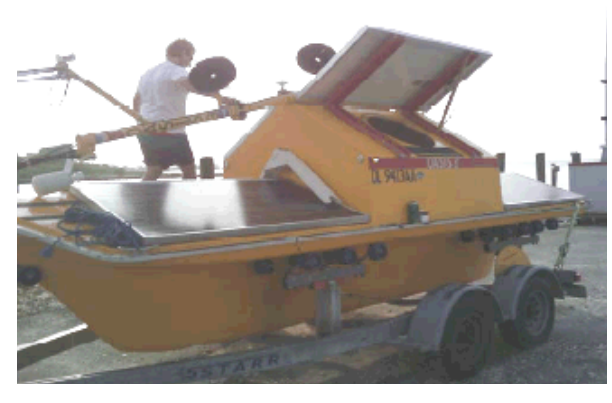

Figure 5a OASIS PLATFORM

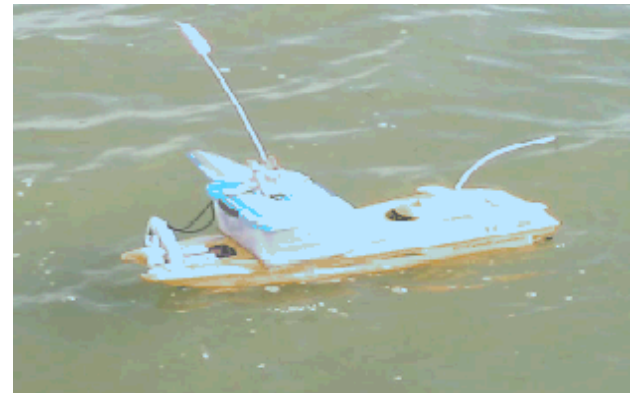

Figure 5b AQUABOT

\subsection{Student Projects at the University of Maryland College Park}

At the University of Maryland College Park (UMCP), there was no difficulty finding qualified applicants for this internship exchange program. Students were very interested in leaving their home institution over the summer to participate in a research experience elsewhere in Maryland. This was particularly appealing since the stipend and benefits were considered quite generous. The applicants chosen at UMCP were felt to be the best match for the 2 projects at MSU and 1 project at UMES that were available to us. A sophomore, a junior, and a graduating senior were selected, and two of these three students were African American.

Two of our incoming summer interns came from UMES and one, a woman, came from MSU. On campus housing was offered to all three of these students since housing in College Park is difficult to come by and is expensive. We matched them up with three projects in the Aerospace Engineering Department at UMCP: a robotic rover project supervised by Dr. David Akin in the Space Systems Lab, a near-space balloon launch project supervised by Dr. Mary Bowden, and a commercial aviation fuel consumption analysis project supervised by Dr. Derek Paley. These projects are described in more detail below:

\section{1) System Upgrades to a Small Planetary Rover}

The UMCP Space Systems Lab has been developing robotics for space and planetary surface applications. Rover is a servo controlled mobile robot created by a previous student at the lab. Modifications were made to Rover's programming allowing it to be controlled remotely using an onboard netbook. Tilt and pan capabilities were added along with a digital camera from a robotics kit, and part of a servo controlled robotic arm was designed to be controlled using a $\mathrm{C}++$ kinematics library. 


\section{2) Near Space Payloads and Balloon Launch Operations}

The Balloon Payload Group of the UMCP Space Systems Lab has been working on a number of different types of payloads that are launched into the upper reaches of the atmosphere on weather balloons. Numerous engineering challenges have been worked through to accomplish a couple of different goals this summer. The first objective was to design a payload to set a new altitude record for amateur ballooning. This new record was successfully established with a launch on July $10^{\text {th }}$ that ascended to $128,379 \mathrm{ft}$, almost $3,000 \mathrm{ft}$ over the previously established record. The next goal of the summer was to design and test a payload that could be assembled by blind high school students attending a summer science academy sponsored by the National Federation of the Blind (NFB). These payloads, which include a GPS receiver and a radio, were successfully assembled and launched on large party balloons to measure temperature and pressure characteristics in flight (Figure 6).
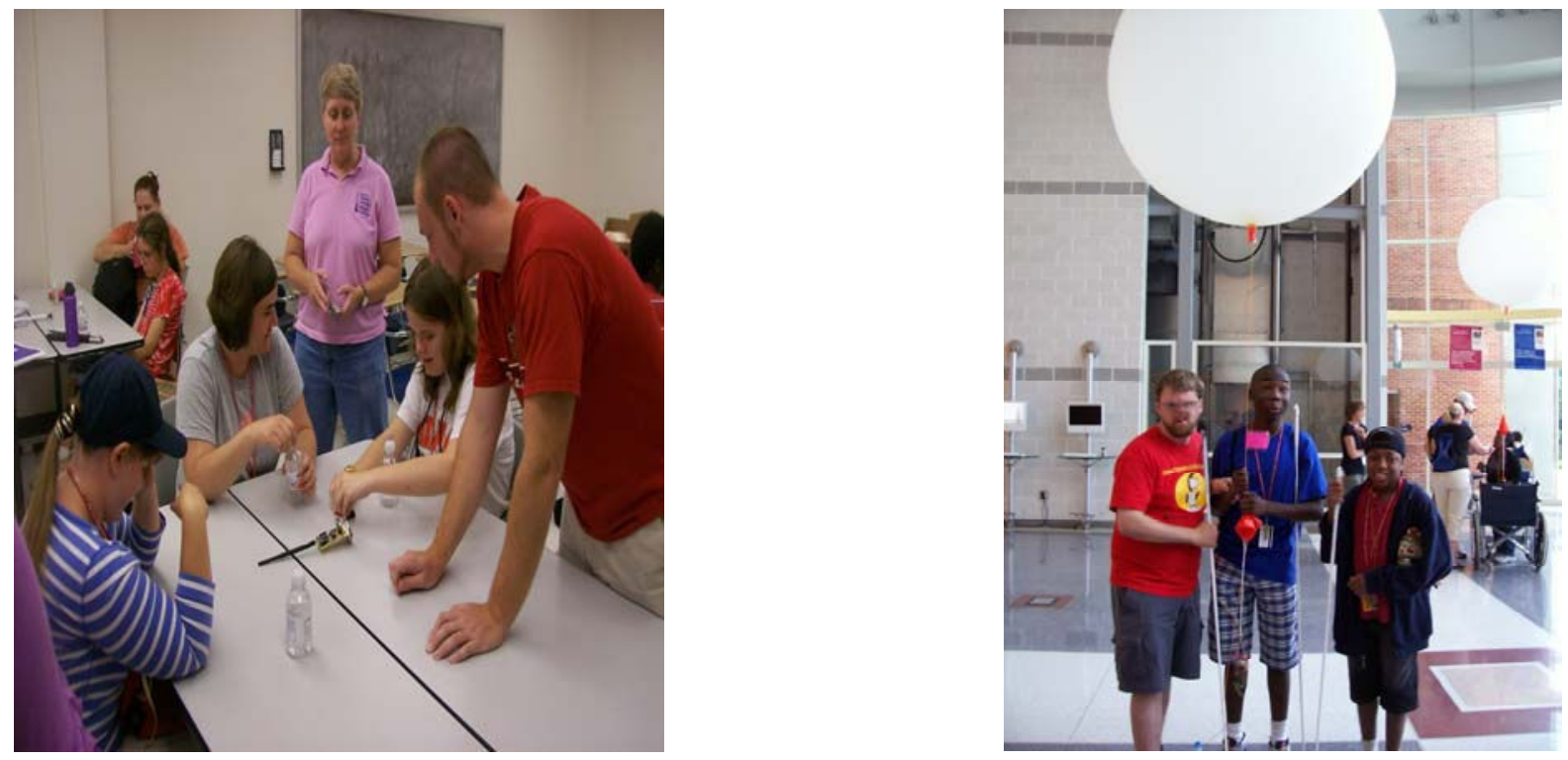

Figure 6 - National Federation of the Blind - Summer Science Academy

\section{3) Commercial Aviation Fuel Consumption due to Flight Delays \& Rerouting}

This project investigated fuel consumption in commercial aircraft due to relevant flight delay statistics and their associated causes. According to the Joint Economic Committee (JEC), 740 million dollars lost in the year 2007 due to commercial flight delays were attributed to fuel consumption. Data statistics for most recent years, 2007-2008, were examined in depth to observe the frequency of delay types and their effects on fuel consumption. Delay types considered were taxi delays, weather delays, NAS (National Aviation System) delays, and airborne holding delays, as well as reroute related delays. Time series plots, histograms, scatter plots, bar and line graphs, comparison plots, as well as geographical plots were all used to investigate phenomenon in the NAS that affect fuel efficiency. Also, a case study was conducted to observe the variation in similar flights and their effect on fuel consumption, and to observe the differences in taxi'ing, time airborne, and other relevant fuel related delays for common days, aircraft, airports, and flight distance groups. Conclusions from these studies may help airlines conserve fuel in the future despite flight delays and rerouting. 


\subsection{Final Presentations}

All participating students presented their work at a seminar hosted by NASA GSFC at the end of the summer (Figure 7). Having the seminar at GSFC emphasized the connection to this major employer of aerospace-related engineers in Maryland and the connection to NASA in general. A tour of the center was included in the seminar. The quality of the presentations was included in the assessment of the students' performance. It was clear that some of the students had more experience in making presentations than others. Some additional coaching in this area may have been beneficial.

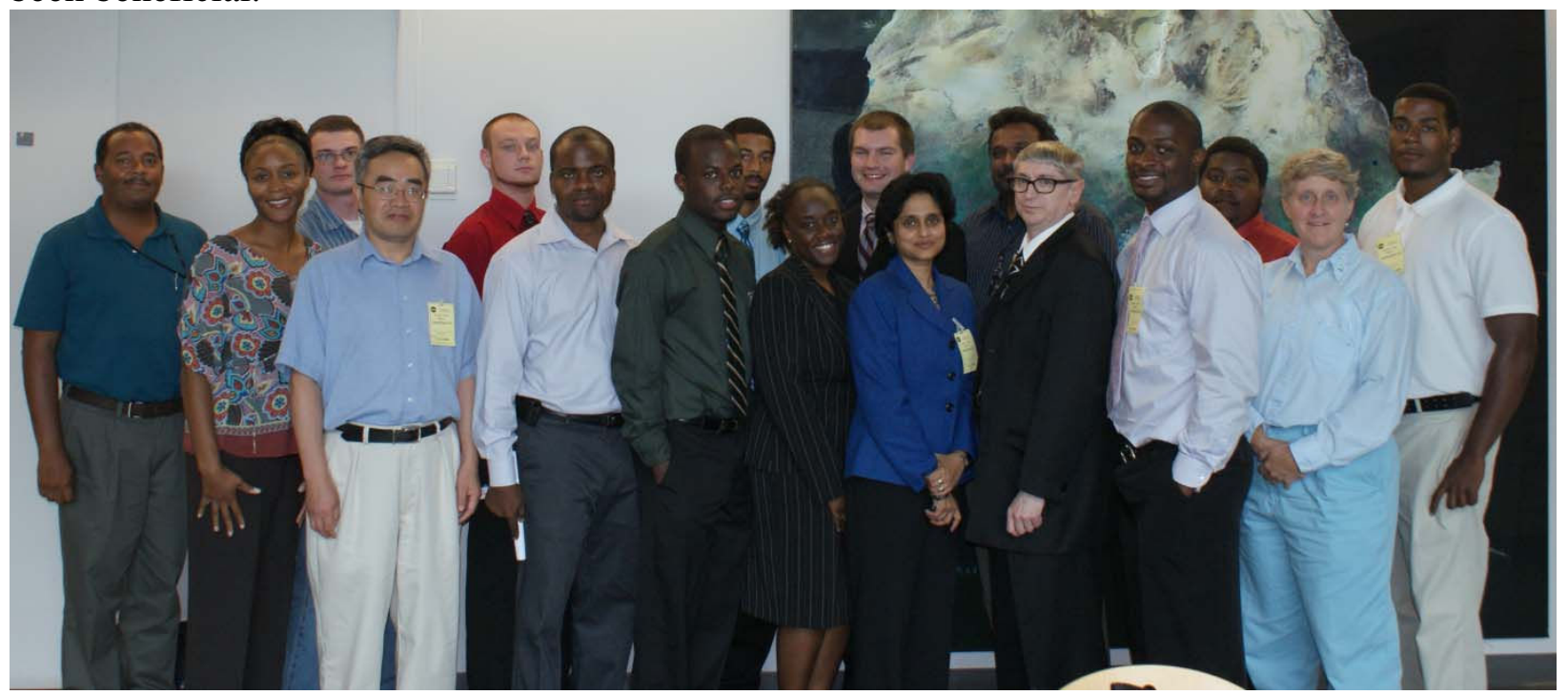

Figure7. Students, faculty, NASA, MDSGC personnel at the GSFC research seminar.

\subsection{Preliminary Outcome Assessment}

Our preliminary assessment of student learning outcome has led us to conclude that this exchange program has achieved a considerable measure of success. Undoubtedly, adapting to different campus cultures and working with various people in diverse communities helped students to develop important life-skills besides honing their academic and engineering skills. In the context of the summer exchange program the participating students also developed a broader understanding of the learning outcomes as delineated by ABET in their Engineering Accreditation Criteria ${ }^{[14]}$. In all of the projects undertaken by these students this summer, they clearly had to apply their knowledge of mathematics and engineering, perform experiments and/or analyze data, recognize realistic constraints to their research project, and work on interdisciplinary teams. In addition, they were exposed to the professional side of engineering and to the need for clear communications both during the summer and most especially at the end of the summer with their final presentations. These experiences will serve them well in the remainder of their undergraduate curriculum and in their subsequent engineering endeavors.

All nine exchange students indicated that their summer experiences were interesting and beneficial to their future career development. By being exposed to hands-on research projects that were closely aligned to NASA's strategic enterprises in earth and space sciences, these students have not only enhanced their problem solving abilities and research capabilities but have gained a better understanding of workforce needs of NASA. MSU and UMCP are close to 
NASA GSFC at Greenbelt and NASA GSFC's Wallops flight Facility is about 40 miles from UMES. This proximity allowed some of the exchange students to work closely with NASA engineers and scientists in addition to their assigned faculty mentors during the summer. A tour of the Greenbelt facilities arranged for the summer exchange students provided an excellent overview of how large scale projects are executed in multidisciplinary teams in a systems engineering framework. The students got an opportunity to present their work at the conclusion of the project at NASA GSFC, Greenbelt to an audience consisting of the faculty mentors, MDSGC directors, and NASA personnel, and other engineers. The experience of presenting before a professional audience and answering a variety of questions reinforced the importance of effective communication skills to the students, and the pivotal role it plays in professional life. The quality of the presentations was included in the assessment of the students' performance. It was clear that some of the students had more experience in making presentations than others, and in future we would recommend that emphasis be placed on presentation skills throughout the summer for all student interns.

The faculty mentors and the MDSGC directors from different campuses in Maryland already had a close working relationship prior to the exchange program. Successful execution of the exchange program and the close interaction has generated interest among the faculty mentors to explore similar collaborative opportunities in the future. This type of program is now recognized to be of significant value to the mentors as well as to the students, not just for the work accomplished through the summer but for the relationships fostered by this exchange. Some of the students are still in touch with their faculty mentors, integrating their research experiences into their capstone senior design projects. A senior student from UMES, who worked as a summer exchange student at MSU, is now pursuing graduate work at MSU. Also, if this program were to be extended in the future to some of the community colleges in the state, we would undoubtedly see some of the best community college students transferring to a four-year degree program as a result of a summer internship experience, where they might not have felt motivated or confident enough to do so otherwise. Recruitment and inclusion of community college students may represent an important step in broadening the socio-economic diversity of the four-year college population.

There is no question that all of the mentors and students involved in this program felt this experience was a valuable one. More rigorous determinations of the success of the program will come from follow-up interviews with the students, and detailed assessments from the mentors. In addition, the true measure of the success of the program will be found through the longitudinal tracking of the students. This system contacts the students on a roughly yearly basis as they continue in their education, and through their first job. They are also asked to assess if the experience has been of benefit to them as they progress along their career path. The number of students who go on to higher education and/or employment in aerospace-related areas will serve as another measure of the success of the program. We will be monitoring the presentations and publications that result from the students' internship work to determine the impact of their work in the engineering field.

Overall, it seems clear that this program was a success but further tracking and feedback will provide us with more information on what were the most essential features of the summer internship and how to do things better perhaps in the future. One recent comment, for example, 
from one of our students, emphasized the fact that for students working singly on their research project over the summer, field trips or other forms of social interaction with other student interns are very important. Similarly, another student mentioned that one of the best parts of the internship experience for him was working with other interns in the same office because of the bonding effect - perhaps this should be recognized as a desirable arrangement if it can be accomplished.

This experiment of exchanging undergraduate students between campuses in Maryland for a summer internship experience has yielded very good results, more than sufficient to recommend that the model be followed, if resources permit, between any set of neighboring colleges and universities, particularly if there is sincere interest in strengthening ties between the institutions. The benefits for the both students and mentors are quite clear, first in terms of engineering experience and professional development, as well as establishing ties that may lead to future collaboration. Equally important from a societal point of view, is the inclusion of a more diverse population in our future engineering workforce, not to mention a more experienced and skillful set of future engineers.

\subsection{Acknowledgment}

We gratefully acknowledge the support from NASA through grant \# NNG05GE74H to Johns Hopkins University. We would like to thank Ms. Janie Nall at GSFC for working with the project team from the inception of the project and for arranging the research seminar at GSFC. The project team would also like to thank Mr. Geoff Bland (NASA GSFC's Wallops Flight Facility) and Mr. Dillard Menchan(Chief, Equal Opportunity Programs at GSFC) took time out of their busy schedule to listen to the presentations and provide advice and words of encouragement to the students at the research seminar. Dr. Keith Hargrove was the team member from MSU during the writing of the proposal; upon his departure from MSU, Dr. Chen became the representative from MSU. We would also like to thank all the faculty mentors at MSU, UMCP, and UMES who worked with the students. The summer exchange students Ms. India Jacobs, Mr. Jonathan Skeete, Mr. Dayvon Green (all from MSU); Mr. Jonathan Beatus, Mr. Adam Morris, Mr. Benjamin Phillips (all from UMES); Mr. Jarred Young, Mr. Xavier Pratt, and Mr. Darren Taillie (all from UMCP) did a splendid job over the summer; their efforts are also gratefully acknowledged.

\section{Bibliography}

1. Birdsong, C., and Schuster, P., "Research in the Undergraduate Environment", Proceedings of 2006 Annual Conference and Exposition of American Society for Engineering Education, June, 2006, Chicago, Illinois, USA.

2. Eisenman. S., and List, G., "The Undergraduate Research Advantage : The Split Perspective" Proceedings of 2004 Annual Conference and Exposition of American Society for Engineering Education, June, 2004, Salt lake City, Utah, USA. 
3. Peten, G., Sawhney, A., and Badger, W., "Overview of Summer Research Program for Undergraduate Students in Construction", Proceedings of 2002 Annual Conf. and Exposition of American Society for Engineering Education, June, 02, Montreal, Canada.

4. Varde, K.S., “ Broadening Engineering Education Through International Exchange Program”, Proceedings of 2004 Annual Conference and Exposition of American Society for Engineering Education, June, 2004, Salt lake City, Utah, USA.

5. Lopatto, D., "Survey of Undergraduate Research Experiences (SURE): First Findings", Cell Biology Education, 3, pp. 270-277, Winter, 2004.

6. Russell, S. H., Hancock, M. P., and McCullogh, J., "The Pipeline: Benefits of Undergraduate Research Experiences", Science, 316, pp. 548-549.

7. Mehta, S., and Kou, Z., "Designing Better Education in the Age of Globalization by Building Partnerships, Connecting People, and Promoting Globalization", Proceedings of 2005 Annual Conference and Exposition of American Society for Engineering Education, June, 2005, Portland, Oregon, USA.

8. Summer Undergraduate Research Fellowship (SURF) - Available Online :

http://www.surf.caltech.edu/applicants/index.html

9. Summer Undergraduate Research in Engineering/Science Programs (SURE) - Available Online : http://www.sure.gatech.edu/

10. Engineering Undergraduate REsearch Konference \& Assembly(EUREKA) - Available Online : http://www.scivee.tv/node/10433 (UCSD)

11. AIRSPACES( Aerial Imaging and Remote Sensing for Precision Agriculture and Environmental Stewardship) Available online : $\underline{\mathrm{http}: / / \mathrm{www} . u m e s . e d u / \text { airspaces }}$

12. Nagchaudhuri, A., Hitchener, P., Louis, D., and Moisan, J., "Integration of State of the Art Simulation Software Tools for Guidance and Control of an Under-Actuated Surface Autonomous Vessel", Session 1478, Proceedings of the 2004 ASEE Annual Conference, Salt Lake City, June 2004, Available Online http://soa.asee.org/paper/conference/paper-view.cfm?id=19904

13. YSI6600V2: Information available online at the URL http://www.ysi.com

14. ABET Engineering Accreditation Criteria : http://www.abet.org/Linked\%20Documents UPDATE/Criteria\%20and\%20PP/E001\%2009-10\%20EAC\%20Criteria\%2012-01-08.pdf 